\title{
Jianhua Zhang
}

Issa Fowai

Ke Sun

http://dx.doi.org/10.21278/brod67204

ISSN 0007-215X

eISSN 1845-5859

\section{A GLANCE AT OFFSHORE WIND TURBINE FOUNDATION STRUCTURES}

UDC 629.5(05) 621.548:624.157

Review paper

\begin{abstract}
Summary
Energy poverty and climate change are crucial issues we face in our societies. Offshore wind energy has been a reliable solution to both of these problems - solving our growing energy problems while reducing $\mathrm{CO}_{2}$ emission. Innovative foundation design is one of the setbacks faced by this industry. Designing and constructing a cost effective offshore wind farm is greatly hampered by technical and infrastructural challenges, especially in foundation structures. This paper provides a detailed overview of issues related to this problem, with the aim of eliminating the frequent misunderstandings which can arise among engineers and investors working in the offshore wind energy sector. It begins by investigating the latest data and recommendations regarding the design and deployment of various kinds of offshore wind turbine (OWT) foundations. It provides a framework which enables us to study the different OWT foundations, including prototypes and their limitations. Various structural failure modes are highlighted and corrosion measures are presented. Moreover, various removal methods of support structures are put forward. Finally, this paper presents the setbacks preventing the spread of offshore wind energy and the future works for offshore wind energy applications.
\end{abstract}

Key words: $\quad$ Renewable energy; offshore wind turbine; foundation; deep offshore design.

\section{Introduction}

There is a pressing need to accelerate the development of advanced energy technologies in order to address the global challenges of clean energy, climate change and sustainable development [1]. Offshore wind energy is the 21 st century's fastest growing source of renewable energy. Investing in this industry is a bright idea for both developed and developing countries. According to statistical report studies from the European Wind Energy Association (EWEA), 418 new OWTs, in 13 wind farms, worth between $€ 4$.6 billion and $€ 6.4$ billion, were fully grid connected in 2013, totalling 1567 MW, 34\% more than in 2012. 
Offshore wind energy accounted for $10 \%$ of the total EU power installation in 2012, one percentage point more than in 2011. The EWEA (see Table 1) reported that as of 2014, the UK has the largest amount of installed offshore wind energy capacity in Europe (4494.4 MW) - 55.9\% of all installations. Denmark follows with 1271 MW (15.8\%). With 1048.9 MW (13\% of total European installations), Germany is third, followed by Belgium (712 MW: 8.8\%), the Netherlands (247 MW: 3.1\%), Sweden (212 MW: 2.6\%), Finland (26 MW: 0.3\%), Ireland (25 MW), Spain (5 MW), Norway (2 MW) and Portugal (2 MW) [2-4]. The rest of the world is in a technological battle to catch up with European offshore development. Over the past decade China and Japan have shown tremendous effort in offshore wind energy. At the end of 2014, China accounted for $45.1 \%$ of the global wind market. The two main factors driving growth of offshore wind energy applications for China are its growing energy needs and the adopted policy to promote utility companies to develop at least $3 \%$ of their energy portfolio in non-hydropower renewable resources [5]. Even though China's offshore wind industry is still in its nascent stage, they have made unyielding efforts to meet their energy demands while curbing global warming. The $12^{\text {th }} 5$-year plan for renewable energy $(2012)$ states that the Chinese Government's goal for 2015 is $5 \mathrm{GW}$ installed offshore wind power, which will increase to $30 \mathrm{GW}$ by 2020 [6]. In the struggle to meet these targets (national, continental or global) OWT projects has been moved into deeper seas where the wind can be full harnessed, and because of these increasing water depth foundation structures have become an important cost factor of OWT structures.

Table 1 European OWT statistics in the end of 2014 (Data from EWEA)

\begin{tabular}{|l|c|c|c|c|c|c|c|c|c|c|c|c|}
\hline Country & BE & DE & DK & ES & FI & IE & NL & NO & PT & SE & UK & Total \\
\hline $\begin{array}{l}\text { No. of } \\
\text { farms }\end{array}$ & 5 & 16 & 12 & 1 & 2 & 1 & 5 & 1 & 1 & 6 & 24 & 74 \\
\hline $\begin{array}{l}\text { No. of } \\
\text { Turbines }\end{array}$ & 182 & 258 & 513 & 1 & 9 & 7 & 24 & 1 & 1 & 91 & 1301 & 2488 \\
\hline $\begin{array}{l}\text { Capacity } \\
\text { installed } \\
\text { (MW) }\end{array}$ & 712 & 1048.9 & 1271 & 5 & 26 & 25 & 247 & 2 & 2 & 212 & 4494.4 & 8045.3 \\
\hline
\end{tabular}

To make offshore wind energy cost-competitive with it onshore counterpart technical and infrastructural difficulties - such as problems with foundations - are among the primary challenges for designing and constructing a cost effective offshore projects. Recently, however, a number of entirely new concepts or ones that are adapted, from the oil and gas industry for example, have been introduced to better deal with these challenges. Most of the OWT projects are mounted on fixed-bottom foundation structures. As of 2013, Japan for instance had a total of $49.7 \mathrm{MW}$ of offshore wind energy installed capacity of which 45.7 MW rely on fixed-bottom foundations [7]. The advantages and disadvantages of each design concept are difficult to assess in a comparative and fair way.

This paper provides a framework for improving our understanding about the different OWT foundation structures currently deployed in offshore wind farms. Firstly, the various foundation types, including prototypes and their limitations will be introduced. Transportation and installation methods will be further discussed. Various structural failure modes will be highlighted and corrosion measures will be presented. A brief overview of removal methods of OWT foundations will be provided. Finally, future recommendations hindering offshore wind energy development will be outlined. 


\section{Forms of OWT foundations and limitations}

OWT foundation component plays a significant role in making an offshore wind farm cost-competitive. OWT foundation is the part of the support structures which transfer the loads acting on the structure directly to the seabed. Technological advancement has presented OWT with foundations of different shapes, sizes and materials. In selecting a cost-effective foundation, special considerations are given to the following factors as they greatly influence the economics of the project: soil conditions, loads (structural dynamics as wind and wave loads are both dominant), transportation and installation and water depth. The depth of the water for instance, is a crucial cost-factor in determining the type of foundation to be used for a specific OWT project. Different water depth poses different engineering challenges for OWT foundations. Presently, OWT foundation concepts include mono pile, gravity-based, tripod, jacket, suction bucket and different floating structures. Below is a detailed description of these various types of foundations deployed in offshore wind farms.

\subsection{Mono pile foundations}

Mono pile foundations are made of steel plates which form steel tubes with diameter of $4 \mathrm{~m}$ to $8 \mathrm{~m}$ and with length of around $60 \mathrm{~m}$. Mono piles are relatively light support of about 700 tons [8]. Determined by the seabed conditions, these steel piles are driven into the seabed by either large impact or vibratory hydraulic hammers (Figure 1), or the piles are grouted into sockets drilled into rock. The standard mono piles (those without lateral support) are mainly used in transitional water depth up to $25 \mathrm{~m}$, while mono piles with lateral support braces are suitable for depth from $25 \mathrm{~m}$ to $40 \mathrm{~m}$. Mono piles are suitable for semi-hard seabed, as hard seabed might lead to deformation of the steel piles during installations. When evaluating the resistance of the soil against the pile load, factors such as pile dimension, strength and deformation properties of the soil and shear stress properties need special considerations. Materials properties such as stiffness and fatigue limit the deployment of the mono piles in deeper waters as steel materials are susceptible to fatigue due to dynamic responses from waves and current loading. The risk of pile pull out should be carefully evaluated in the design process. Besides, construction of this foundation requires minimal seabed preparation. Overall deflection (lateral movement along the mono pile) and vibration, are limiting conditions for this type of foundation structures $[9,10]$. As a fact, mono pile foundations are widely used due to their simple geometric shape and less installation cost. It total, 2031 mono pile wind turbines installed capacity of $6423.9 \mathrm{MW}$ are currently operating in the end of 2013 [1, 8]. 177 individual mono piles (including two substations) have been installed on the world's largest offshore farm- London Array (installed capacity of $630 \mathrm{MW}$ ) in UK, length of pile is $68 \mathrm{~m}$, diameter is $5.7 \mathrm{~m}$ and weigh as much as 650 tons, with a transition piece of height up to $28 \mathrm{~m}$ weighing between 245 tons and 345 tons.

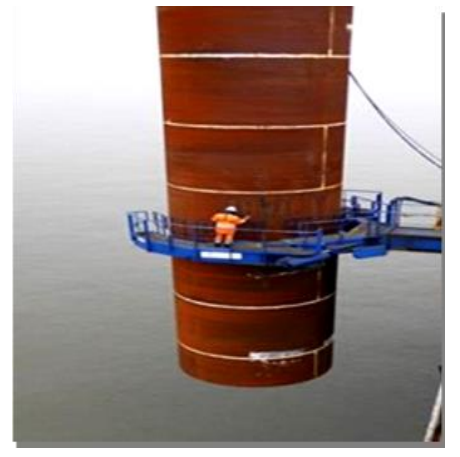

Fig. 1 Mono pile foundation

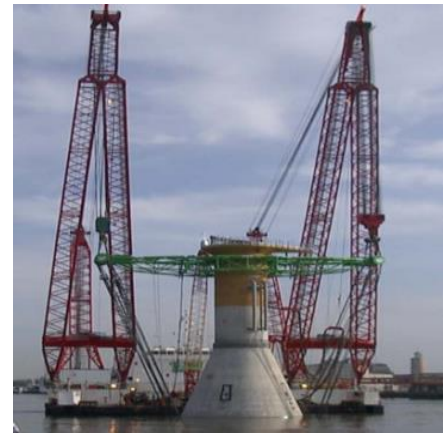

Fig. 2 Gravity-based foundation 


\subsection{Gravity-based foundations}

This structure comprises of slender steel or concrete pile like substructure fixed on heavy reinforced concrete foundations. This type of foundation is relatively heavy compared to the mono pile as it is usually made out of concrete materials (Figure 2). As the name implies it relies on the weight of the gravity base, which applies vertical pressure to the area below the stand on the seabed to support the structures and resist overturning. Gravity-based foundations are well suited for homogeneous soils, with compact rocks and granites. External forces and bending moments transmitted by the turbines are transferred directly through the base of the foundation. The risk of shear failure under the base structure needs to be evaluated. Since concrete material is widely used to construct this type of structure, they are mostly used in shallow water depth between 0 to $25 \mathrm{~m}$. However, in Belgium over the Thornton Bank offshore Wind Farm 6 gravity-based foundations were constructed in water depth up to $28 \mathrm{~m}$ [11]. The size and weight makes it extremely difficult to transport and install, thereby limiting their deployment in deep water. Enormous port space is also needed to construct these structures. Even though concrete is a very cheap material, it is extremely expensive and time consuming to install, therefore it is not a preferred solution [12]. However, these types of foundations can be easily removed upon decommissioning.

\subsection{Tripod foundations}

With continuous growth in the offshore wind industry, the demand to take project into deeper water called for a more stable foundation structure. Just like the tripod we use for our cameras, the tripod foundation is a three legged foundation with a wider base and an anchor pile driven to the seabed to hold the foundation firm (Figure 3). In 2014, 0.9\% of European offshore wind turbines were mounted on tripod foundations [4]. These foundations have high resistance of dynamic responses like wave and current loading making them ideal for deeper waters. Tripods are suitable for water depth between $25 \mathrm{~m}$ to $50 \mathrm{~m}$. For offshore wind turbines of larger size, this type of foundation faces financial problems as they take more time to construct and are difficult in transport.

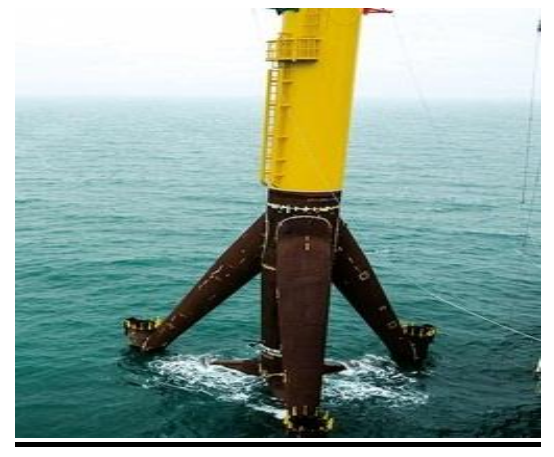

Fig. 3 Tripod foundation

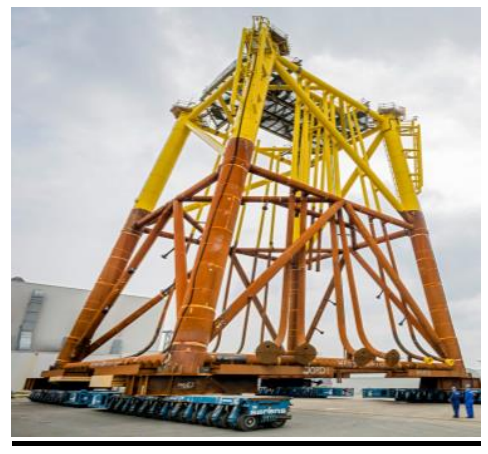

Fig. 4 Jacket parts

\subsection{Jacket foundations}

This type of foundation is commonly used to support oil platforms and it is the second widely used foundation structure for offshore wind projects. The jacket is normally a three or four legged jacket/lattice structure (Figure 4), consisting of corner piles interconnected with slender steel bracings to form a lattice tower. Loads are transferred through the members mainly in axial direction (just like truss structures). This type of foundations is suitable for water depths from $30 \mathrm{~m}$ to $80 \mathrm{~m}$. The large base of the foundation helps the structure to withstand overturning. This type of foundation is relatively stiffer than the mono pile foundation making it less affected by the wave and current load. The transportation is moderately difficult and expensive. Maintenance cost is also high. However, installation cost 
is lower, since structural elements can be partially or fully assembled before floated for installation. Extra corrosion protection measures have to be considered as they might lead to fatigue in the structural components. Protective coating is used for the steel components in both the atmospheric zone and splash zone, while submerged component is cathodically protected.

Since the deployment of world's first offshore jacket structure in the Alpha Ventus wind farm (water depth of $30 \mathrm{~m}$ ) in 2009, other offshore projects like the Beatrice demonstrator project (water depth of $45 \mathrm{~m}$ ) were accomplished with the help of jacket foundations. Engineers as well as researchers have worked enthusiastically to modify this structure. Shi et al. [13] carried out a simulation for a 5 MW OWT located in the Korean southwest sea. Two different jacket support structures (X-braces and Z-braces) were designed and they found that Z-braces jacket have a comparable dynamic properties comparing with X-braces. Further research work on this structure can be of relative importance to the offshore foundation technology. Jianhua et al. [14] used the ADINA code to investigate the impact of ship on jacket type OWT foundation. They concluded that joints with greater wall thickness have stronger energy saving and anti-collision ability.

\subsection{Twisted jacket foundations}

A recent innovation by a U.S. company has given rise to a twisted jacket foundation (Figure 5), where legs twist around central column. These structures are easier in manufacture and installation than conventional jacket foundations, helping drive down the cost of energy for offshore wind. Twisted jacket was first installed by wind-smart in Hornsea Zone (UK), jointly funded by Mainstream Renewable Power, Dong Energy and the Carbon Trust. This type of foundations are designed for water depth up to $30 \mathrm{~m}$ to $50 \mathrm{~m}$, and they use less steel materials compared to traditional jacket foundations [15]. With fewer nodes and components compared to the traditional jacket structures, fewer welds are needed, the fabrication cost of these structures are about $20 \%$ less expensive than a traditional jackets with many braces. The twisted jackets was the first structure ever installed in Round 3 waters to support the Hornsea meteorological mast tower in 2011 [16].

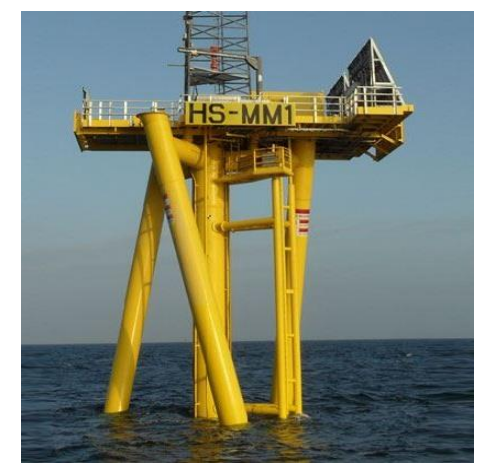

Fig. 5 Twisted jacket deployed in Hornsea (UK)

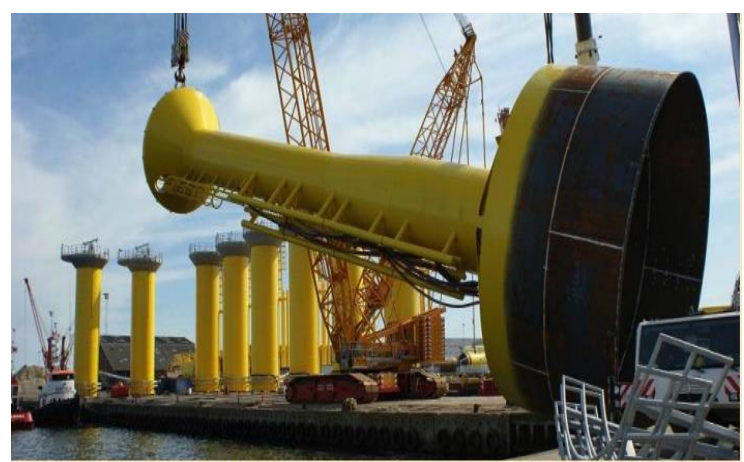

Fig. 6 Suction bucket structure (Photo: Dong Energy)

\subsection{Suction bucket foundations}

This foundation type has been tested and proven in the oil industry for more than 20 years, but quiet recently its application for OWT has been proven. This structure is made from steel material in the form of a bucket about $60 \mathrm{~m}$ in diameters as shown in Figure 6. Compared to conventional steel piles, this foundation uses less steel materials, making it more cost effective and installation period relatively shorter. Since 2001 MBD Offshore power in collaboration with Aalborg University pursued intensive research work on this structure, a medium scale testing in sand was carried out in Frederikshavn, while a laboratory testing in 
sand was carried out in Aalborg University. In 2003 a prototype was developed for a 3 MW Vestas turbine (Frederikshavn, Denmark), another prototype was made available for a $5 \mathrm{WM}$ Enercon turbine in 2005 (Wilhelmshaven, Germany) [17]. Leading entrepreneurs in the offshore industry, Dong Energy, sunk the first this type of structures at the Borkum Riffgrund 1 offshore wind farm, a few kilometres from Northwest of Germany in the North Sea as shown in Figure 6 [18].

\subsection{Floating foundations}

The concept of a floating wind turbine has been researched on since the mid-1990s. In recent years European Offshore Tech-giant has given birth to what is looked upon as the future of offshore wind market-deep offshore designs [19]. The commercialization of this new concept will not only reduce the installation period but shall greatly decrease the total cost of an OWT project. Many of the offshore wind farms (Beatrice, Thanet, DanTyst, Donghai Bridge etc) are mounted on fixed bottom foundation structures. These types of structures are not feasible for water depth of $50 \mathrm{~m}$. New foundations concept with no water depth limitations has to be developed in order to fully harness the wind at sea. Floating concepts have been borrowed from the OWT and gas industry. But the oil and gas design engineering legacy cannot be adopted as it is. The NREL 5 MW turbine weighs about 700 tons, while an oil drilling platform could weigh about 70000 tons. This difference in weight greatly influences the direct deployment of oil and gas floating structures in offshore wind farms [20]. Structural dynamics is a very crucial issue for the deployment of floaters, since these structures have 6 degrees of freedom, which can be excited by wave, wind and ocean current loads, the entire system should be moored and stabilized using mooring lines, ballasting etc.

In European new foundation prototypes, floating foundation structures are constantly being developed as OWTs get bigger and projects are moved into deeper waters. Skills and technologies developed in Europe are deployed in many different parts of the world. Several prototypes of this design exist, since the installation of the world's first large scaled grid connected floating wind turbine, Hywind, in Norway, 2009. In 2011, Principle Power in partnership with EPD and Repsol installed off the Portuguese coast the second large scared floating system-Wind float. This structure is a semi-submersible floater fitted with heave plates at the base of each column. There are three main advantage to the type of foundation: its static and dynamic stability enabling use of commercial OWTs, its design and size allow for onshore assembly, and its design of the Windfloat enables the structure to be fully assembled onshore and towed to its final location [21]. Windfloat (Figure 7, installed in Portugal, 2011), WINFLO (Figure 8, installed in France, 2014) and IDEOL (Figure 9, installed in France, 2014) are all deep water floating foundations recently deployed in European waters. With all this advancement in research and prototype development, very few of these structures have been used for commercial purposes. Installation cost is one of the enormous drawbacks for these types of foundations.

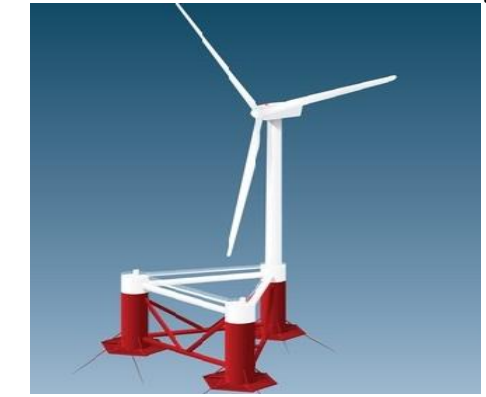

Fig. 7 Windfloat, semi-submersible type

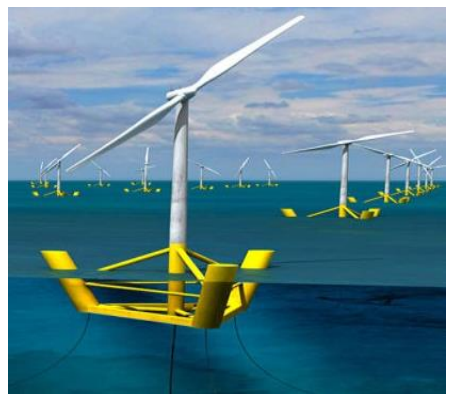

Fig. 8 WINFLO

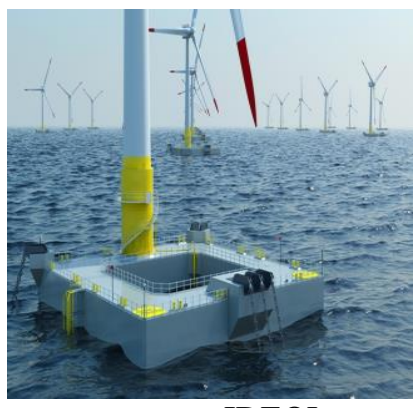

Fig. 9 IDEOL 


\section{Foundation transportation and installation process}

Transportation and installation costs account for a considerable portion of the total budget. Therefore, the duration, workability and equipment availability are crucial to the successful construction of a low-cost offshore wind farm. Specialized transportation, installation equipment (Figure 10) and expertise are required. The various foundation types described above are usually transported to the sites on barges (Figure 11). Depending on the weight and distance from installation sites OWT foundation structure are easily floated to sites thereby reducing the transportation cost. Geometric configuration of the structure integrated transportation and installation technique described by Zhang et al. [22] can be employed as deployed in China's Jiangsu offshore wind project. Wind turbines are also transported in one piece on barges. Transportation experts are required, as a small abnormality in the process can have a considerable impact on the project budget and construction deadlines.

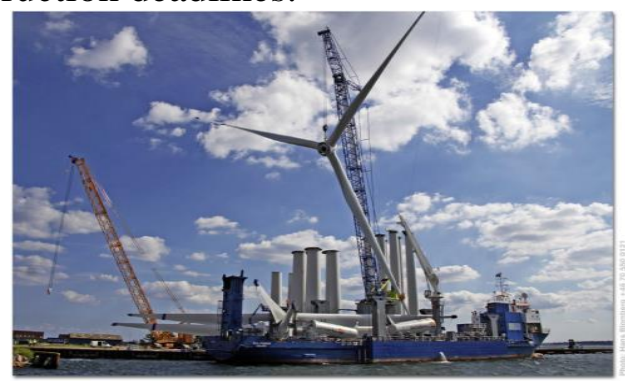

Fig. 10 Crane barge used for wind turbine installation

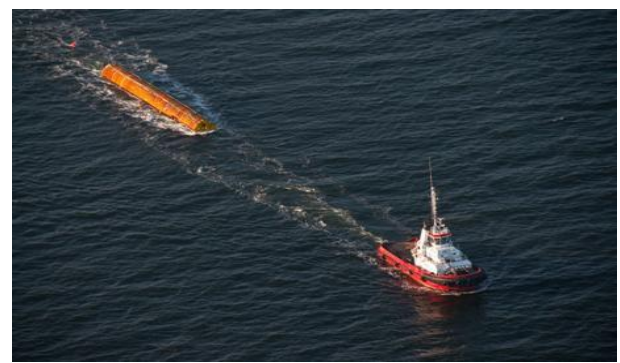

Fig. 11 Transporting offshore wind foundation to site

Foundation installation is a crucial phase to a successful offshore wind project. In Europe offshore wind foundation companies such as Bladt, Sif, Smulders and Aker Verdal with enormous experience are usually hired. Different foundation installation methods have specific effects on the marine habitat, leading to injury or mortality in fish and other aquatic mammals especially during breeding and nursery periods. The most widely used foundation, mono piles, are installed using hydraulic hammer (Figure 12). These hydraulic hammers will drive the piles few meters (up to $20 \mathrm{~m}$ depending on the seabed condition) into the seabed. Pile driveability evaluation and hammer selection should be given special priority. Pile installation process could take a couple of hours or a day depending on the soil properties and environmental conditions. However, mono pile structures require minimal seabed preparation. The speed and progress of pile installation solely rely on the seabed condition. For pile (other steel structures) substructures, special attention should be paid to material fatigue during the installation process, as a small change in stiffness could lead to a great change in structural nature.

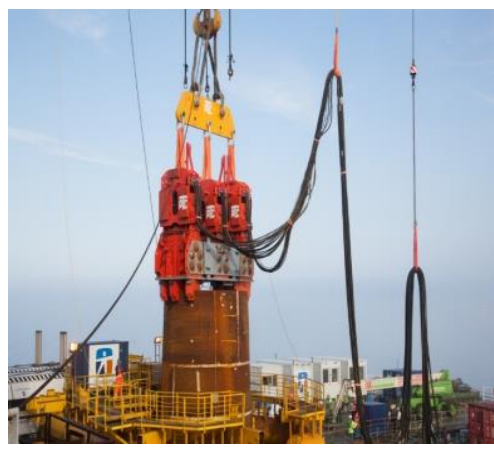

Fig. 12 Hydraulic hammer driving Mono pile to seabed

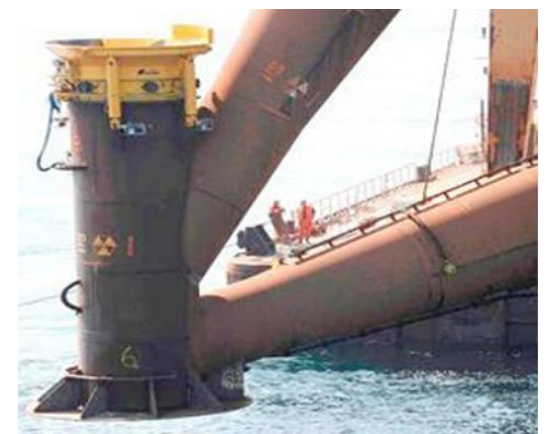

Fig. 13 Pile sleeve on a tripod foundation

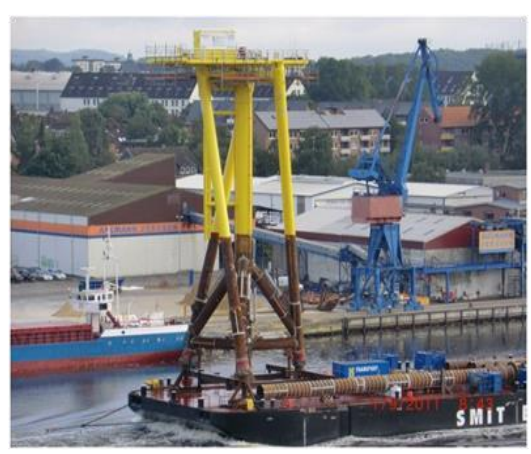

Fig. 14 Transportation and installation of a twisted jacket 
The installation of the jacket foundation for instance, is actually fairly straight forward. Installation operations includes: pile driving, jacket lift, transition lift (only for concrete) and grouting. The anchor piles are fitted to the jacket using pile sleeves (shown in Figure 13), and the connection between the anchor piles and the jacket is established by means of grouting (or casting) the anchor pile in place using high-tension concrete [23]. The twisted jackets, on the other hand are more compact, many of them can be transported per trip to sites by barges as shown in Figure 14, and transportation cost is significantly reduced. The installation and removal operations of the twisted jackets are relatively easier. During installation, no extra offshore welding or underwater work is needed. Less expensive vessels can be used to perform grouting operations. Smaller hydraulic hammers are required for installation. Furthermore, there is no need for larger vessels since the maximum lift weight is less than the mono pile structures.

\section{Failure modes of OWT foundations}

In these severe marine environments where wind turbines are constructed, OWT foundation structures can easily reach some of its limits states (ultimate limit state, fatigue limit state etc.) leading to structural instability issues, failure modes such as shear failure, bearing failure, pile pull-out and large settlements or displacement should be probably evaluated.

Mono piles, the most widely used offshore substructures are faced with stability problems when subject to dynamic loading. Vertical (buckling of piles and shear failure) and lateral (slenderness) failure modes are design safety concern for pile-type structures. Besides, installed mono piles were linked with grouting failure. Grout is the bonding material which is injected into the foundation's annuli to provide structural integrity of the foundation's joints as shown in Figure 15 and Figure 16. Grout is available in different strengths: ultra-low, standard, high and ultra-high strengths [24]. Reliable materials with extremely high strength and fatigue properties and minimal shrinkage such as Ducorit: a pumpable, Ultra-High Performance Cementitious (UHPC) material have been developed specifically to tackle grouting issues in mono pile [25]. Besides fatigue and grouting failure, mono piles are susceptible to pull-out failure mode in sites where soils are erodible. In this situation the pile material deformation properties and soil deformation properties should be carefully evaluated. The type of loads, geometry (usually conical) of pile and method of installation are all factors that greatly influence the mechanical properties (shear strength, bending moment and fatigue) of the pile structure.

A potential risk of slope failure is also a very common phenomenon among tripod and jacket foundations, special evaluation covering, slopes developed during and after installation, natural slopes, wave-induced soil movement, and especially soils susceptible to erosion should be further carried out. OWT foundations are susceptible to dynamic loadings, the continues changing in both magnitude and direction of load such as wave and current load can lead to scour (Figure 17): a phenomenon wherein soil is removed near the pile structure thereby weaken the load capacity. In the design stage consideration should be allocated to cyclic loads caused by wave and current, even though scour can alter a small change in the structural stiffness. Scour protection measures such as gravel mattress or scour mat should be considered. Fatigue on the other hand is relatively sensitive to cyclic loading. 


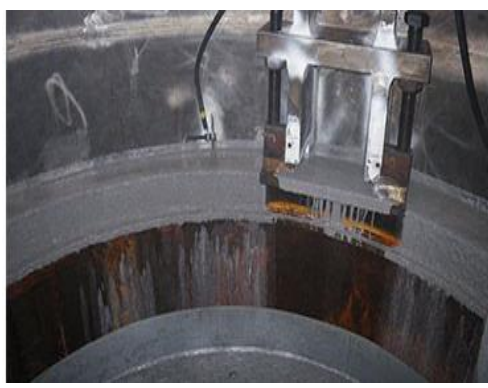

Fig. 15 Grouting material in mono pile foundation. Densit [25]

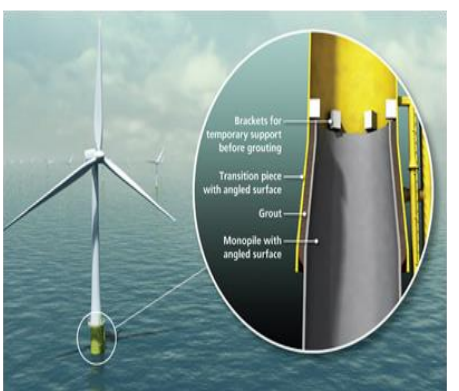

Fig. 16 Conical connection between the transition piece and the pile (DNV)

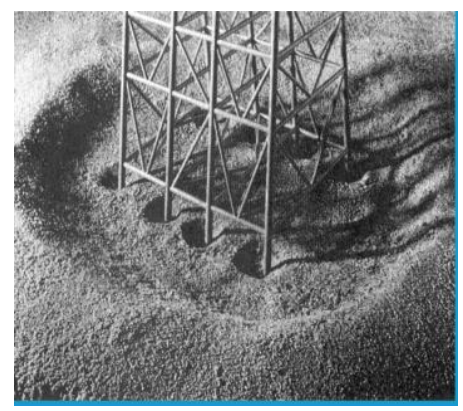

Fig. 17 Scour

\section{Corrosion protection for OWT foundations}

Corrosion protection is a key cost-factor in Operation and Maintenance (O\&M) budgeting of offshore wind farm. Although not often appreciated corrosion is a major risk for OWT foundations. Its effects could mean costly offshore retrofit work, result in the loss of generation and expose operatives to additional health and safety risks [26]. Besides the gravity-based foundations which are often made of reinforced concrete materials, all other offshore foundation structures are vulnerable to corrosion in marine environment. Corrosion protection is there for a crucial issue for OWT projects, as steel materials by default are susceptible to corrosion even in under normal environmental conditions as shown in Figure 18 and Figure 19. Corrosion allowance, cathodically protection and coating are all corrosion protective measures applicable to OWT foundations. The parts of the foundation in the splash zone are usually protected by coating corrosion allowance, and special fatigue requirement is needed since this part of the structure is subjected to dynamic load causing a constant change in stress. The parts of the structure submerged in the water are protected using cathodically protective measures. For foundation structures with seawater in closed compartment cathodically protective methods are also used. When corrosion allowance method is used the thickness of the structural component should be increase. Experts in corrosion protection in steel structure should carry out the inspection and maintenance of these structures.

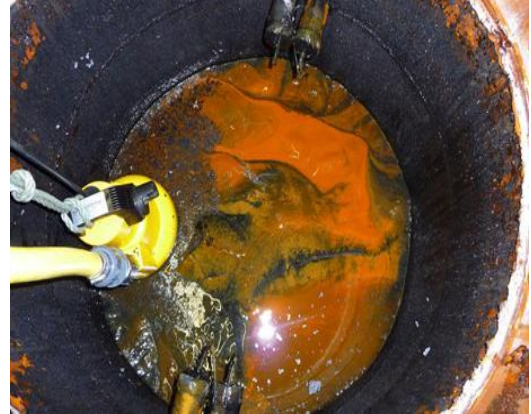

Fig.18 Internal corrosion of mono pile structure

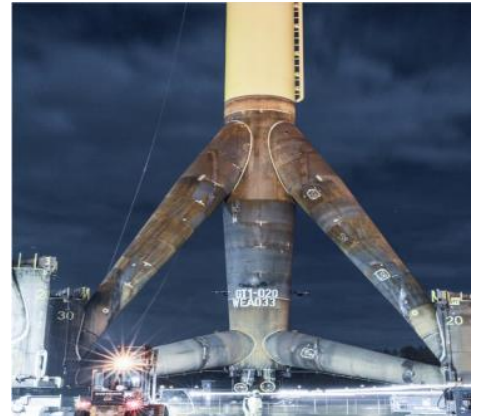

Fig. 19 Corrosion protection system

\section{Removal of OWT foundation}

OWTs do not last forever. Generally, an OWT has a service period of at least 20 to 25 years after which the structure would have to be dismantled without greater harm to the marine environment. During the installation stage of an offshore wind farm, a detailed plan on how the structures will be removed and transported back to shore after service period will be presented to concerned authorities. Besides the environmental and ecological impacts, removal techniques can enormously affect the economics of a given offshore project. Therefore, literature on state-of-the-art removal techniques and equipments are urgent in making offshore wind energy a cost competitive renewable industry. Pearson, Enron Wind, 
UK investigated removal of wind turbines in the UK offshore wind farm, concluding that dismantling of OWTs is a complex process far greater than just removing structures from the seabed [27]. Januario et al. [28] presented a proposal on removal of offshore wind farm.

The method of dismantling foundation structures depends on the foundation type. Some of these structures can be easily re-floated or cut off at seabed. Operational requirements, site characteristics, equipments and contract terms are exceptional for different foundation removal. However, there is very small variation in dismantling methods for different types of foundations. For example, twisted jackets are easier to fabricate due to the use of lesser steel materials. According to a study observed from the American Wind Energy Association, a typical pre-pilled jacket requires 103 welded steel components while a twisted jacket needs only about 49 shown in Table 2 [29]. With lesser node and braces, twisted jackets can be easily removed for reuse in future offshore wind farm. The removal of twisted jacket is done at a minimal cost compared to foundations with pre-installed piles such as mono pile and tripod. The whole twisted jacket structure with piles and caisson sections can be lifted on transportation vessels with the same equipments used for installation. The piles and caisson are accessible from the surface.

Table 2 Components comparisons of pre-pilled jacket and twisted jacket

(Data from Smulders (Thorton Bank): Keystone 2012-SLIDE-Carbin Trust)

\begin{tabular}{|l|c|c|}
\hline Components & Pre-pilled jacket components & Twisted jacket components \\
\hline Transition section & 1 & 1 \\
\hline Legs (sleeves) & 4 & 4 \\
\hline Braces & 40 & 15 \\
\hline Nodes & 40 & 17 \\
\hline Pins & 4 & 0 \\
\hline Integrated upper deck & 1 & 0 \\
\hline Heavy wall sections & 28 & 12 \\
\hline Total & 103 & 49 \\
\hline
\end{tabular}

\section{Foundation setbacks preventing the spread of offshore wind energy}

In developing any successful offshore wind farm, special considerations are given to foundations, since these structures determine the success of an OWT project. In the race to find cost-effective OWT foundations, Europe has taken the lead in making valuable contribution in design and construction of these structures. According to statistics studied from the EWEA, 446 OWT foundations were installed in European water in 2014, which 179 less than in the previous year. These foundations were supplied by six companies: Bladt, Sif, EEW, Smulders, Aker Verdal and Siag. There was a decrease in fix foundation manufacturing in 2013 to 2014, mainly because European nations are looking into the future of offshore wind energy, which is a deep offshore design such as floating foundations. More research work was carried out in order to meet the 2017 deadline of commercializing floating OWT.

Deep OWT designs are undeniably the future of the offshore wind industry, but since the field of deep offshore foundation design (floating foundations) is a new concept adopted from the oil and gas industry, intensive research work is needed to fully understand structural integrity of these types of foundations. What are the impacts when marine animal collides with the mooring and anchoring systems? The effect of these impacts should be carefully investigated. A further research is required to fully analyze the impact of dynamic loadings from tornadoes and typhoons. 
Designing OWT foundation is faced by both human and technological challenges. Additional engineering issues such as increased water depth and complex ground conditions have had it impossible for researchers to catch up with development in the offshore wind industry. As projects are moved to farther offshore, the turbines basically remain the same cost whereas these challenges increase the cost of foundation. OWT foundation cost may account for approximately $30 \%$ of the total project cost. This figure might increase to $35 \%$ when projects are faced with extra extreme environmental challenges in deep water. The increasing cost of OWT foundation has greatly discouraged developing countries in Africa, Asia and South America. Furthermore, these monetary constrains have accounted for a less detail data about soil properties, since scalable portion of soil are tested before construction.

In order to kick start, the development of offshore wind energy in developing countries, state-of-the-art technologies from Europe, Japan and U.S. should be made available to other interested member states in offshore wind energy. A much bigger market could be developed by breaking these inter-continental barriers, and exchange of skills and technologies globally is a foremost stride.

\section{Future work for OWT foundations}

In the mere future special consideration will be given to modelling tools and numerical codes that simulate the whole structural behaviours. Scaled-up model of OWT foundation design and optimization for cost-effective deployment of OWT is crucial, for closing the gap between academic models and application in practice. OWT foundation analysis using numerical methods to fully comprehend the current, wave and wind impact on floating foundations; finite element model for floating OWT will be proposed to help fascinate the commercial deployment of these structures in the harsh marine conditions. Besides the operational and maintenance cost of OWT projects is relatively high, detailed literature on maintenance logistics is vital to eliminate the frequent misunderstandings which can arise among engineers and investors. Offshore wind energy is undoubtedly a capital intensive enterprise; cost reduction studies on deep water foundation structures concept would be further investigated to make offshore wind power cost-competitive with onshore wind power and other sources of clean reliable energy.

The offshore wind energy resource potential is tremendous not just in Europe, where the industry faces rapid development but also in the U.S., Japan, China and South Korea where the need to balance energy production is high. With unprecedented opportunities, the embracement of offshore wind energy could be important trend in the development of wind power industry. Presently, technical bottlenecks and high construction cost among other factors have increased the weakness and uncertainties which adversely affect the offshore wind industry. Well suited policies can act as a crucial turning point in resolving the unique engineering challenges face by the industry.

\section{Conclusions}

The offshore wind market has been growing over the years, but the continued progress of this industry is greatly hampered by the lack of cost-effective foundation structures. The appropriate choice of OWT foundation depends on variables such as water depth, turbine size, soil deformation properties, installation cost and geologic hazards. Large bodies of work on current data and recommendations have been surveyed in this paper. We can summarize the conclusions of the analysis as follows: 
The offshore wind industry in Asia is in a technological war with Europe. Ambitious challenges have been set to catch up with Europe's rapid development. In this region, China and Japan have taken the lead.

Fixed-bottom foundations such as: mono piles, jackets and tripods have been widely deployed in offshore wind farms, due to their water depths limitations, and new innovative designs such as twisted jacket foundation and floating foundation have been developed for commercial use.

Transporting these foundation structures requires high-cost transportation vessels, in cases where sites are closer to shore, foundations could be easily floated to construction sites.

The failing of support structure can be very detrimental to O\&M cost of an offshore farm, potential risk of foundation failure during construction and operation of OWT should be carefully evaluated.

The sea is a risky place to work, besides design and construction considerations, special attention should be given to corrosion protection since most of these structures are made of steel materials.

Dismantling of offshore foundations is more than just removing the structural components from the seabed after service period. Decommission process is unique for different offshore substructures and foundations. Removal of twisted jacket foundation is less expensive since there are no pre-installed piles; the structures can be lifted with the same equipments used for installation.

The availability of reliable numerical code which could efficiently simulate the whole OWT structure can give birth to more innovative support structures which could help enhance development in the cost reduction pathway.

\section{Acknowledgements}

This work was supported by the National Natural Science Foundation of China (No.51409065 and 51209060), Provincial Science Foundation of Heilongjiang (No. E2015051) and Harbin Special Study Fund for Technological Innovation (Grant No.2014 RFQXJ017 and No.2015RQQXJ014 ). Also authors thank Dr. Dianwei Gao, with his help we revised the program.

\section{REFERENCES}

[1] IEA, 2013, “Technology Roadmap: Wind Energy”, Report, [Online], http://www.iea.org/publications/freepublications/ publication/technology-roadmap-wind-energy---2013edition.html.

[2] A. Arapogianna, J. Moccia, and J. Wilkes, 2013, “The European Offshore Wind Industry-Key Trend and Statistics 2012 ”, European Wind Energy Association, pp. 5-10.

[3] G. Cobetta, 2014, “The European Offshore Wind Industry - Key Trend and Statistics 2013”, European Wind Energy Association, pp. 4-13.

[4] G. Corbetta and A. Mbistrova, 2015, "The European Offshore Wind Industry-Key Trend and Statistics 2014", European Wind Energy Association, pp. 3-13.

[5] Xingang Zhao and Lingzhi Ren, 2015, "Focus on the Development of Offshore Wind Power in China: Has the Golden Period Come?”, Renewable Energy, 81(9), pp. 644-657. http://dx.doi.org/10.1016/j.renene.2015.03.077.

[6] M. Kornes, 2014, "China's Offshore Wind Industry 2014," Norwegian University of Science and Technology", pp. 1-25.

[7] A. K. Govindji, R. James, and A. Carvallo, 2014, "Appraisal of the Offshore Wind Industry in Japan”, Carbon Trust, pp. 6-25.

[8] 4coffshore. "Support Structures-Mono pile", [Online], http://www.4coffshore.com/windfarms/supportstructures-for-offshore-wind-turbines-aid268.html 
[9] M.B. Zaaijer, 2006, "Foundation Modeling to Assess Dynamic Behavior of Offshore Wind Turbines", Journal of Applied Ocean Research, 28 (1), pp. 45-57. http://dx.doi.org/10.1016/j.apor.2006.03.004.

[10] Ki-Yong Oh, Ji-Young Kim, Jun-Shin Lee, 2013, "Preliminary Evaluation of Mono pile Foundation Dimensions for an Offshore Wind Turbine by Analyzing Hydrodynamic Load in the Frequency Domain", Renewable Energy, 54(6), pp. 211-218. http://dx.doi.org/10.1016/j.renene.2012.08.007.

[11] K. Peire, H. Nonneman and E. Bosschem, 2009, "Gravity Base Foundations for the Thornton Bank Offshore Wind Farm”, Terra et Aqua, 115, pp. 19-29.

[12] K. Thomsen, 2011, "Offshore Wind: A Comprehensive Guide to Successful Offshore Wind Farm Installation", Elsevier Science, UK, Chap.1.

[13] W. Shi, H. Park, C. Chung, J. Baek, Y. Kim and C. Kim, 2013, "Load Analysis and Comparison of Different Jacket Foundations”, Renewable Energy, 54(6), pp. 201-210.

http://dx.doi.org/10.1016/j.renene.2012.08.008.

[14] Jianhua Zhang, Dianwei Gao, Ke Sun and Ziyang Zhang, 2014, "Ship Impact Behavior on Jacket Type Offshore Wind Turbine Foundation", Proc.33rd International Conference on Ocean, Offshore and Arctic Engineering, San Francisco, CA, pp. 1-7.

[15] G. Matzat, 2014, “Advanced Offshore Wind Tech: Accelerating New Opportunities for Clean Energy”, [Online], http://energy.gov/eere/articles/advanced-offshore-wind-tech-accelerating-new-opportunitiesclean-energy.

[16] K. E. Inc, 2014, "Inward Battered Guide Structure the Twisted Jacket”, Keystone Engineering INC, pp. 2 6.

[17] C. L. Bakmar, 2009, "The Monopod Bucket Foundation-Recent Experience and Challenges Ahead", Hamburg Offshore Wind Conference, Hamburg, Germany, pp. 1-9.

[18] K. Garus, 2014, "First Suction Bucket Jacket is Complete", Offshore Wind Industry [Online], http://www.offshorewindindustry.com/news/first-suction-bucket-jacket-complete

[19] A. Athanasia and A. B. Genachte, 2013, "Deep Offshore and New Foundation Concepts", Energy Procedia, 35(41), pp. 198-209. http://dx.doi.org/10.1016/j.egypro.2013.07.173.

[20] S. Lefebvre and M. Collu, 2012, "Preliminary Design of A Floating Support Structure for A 5MW Offshore Wind Turbine”, Ocean Engineering, 40(2), pp. 15-26. http://dx.doi.org/10.1016/j.oceaneng.2011.12.009.

[21] P. Power. "Windfloat [Online], http://www.principlepowerinc.com/products/windfloat.html

[22] P. Zhang, Y. Han, H. Ding, and S. Zhang,2015, "Field Experiments on Wet Tows of An Integrated Transportation And Installation Vessel with Two Bucket Foundations for Offshore Wind Turbines", Ocean Engineering, 108(11), pp. 769-777. http://dx.doi.org/10.1016/j.oceaneng.2015.09.001.

[23] J. F. Jensen, 2010, "Jacket Foundations for Wind Turbines", International Association of Bridge and Structural Engineering, Denmark.

[24] T. Price, 2012, "Grouting Still a Major Issue for Offshore Wind", Renewable Energy Magazine, [Online],http://www.renewableenergymagazine.com/article/grouting-still-a-major-issue-for-offshore.

[25] D. ID. Ducorit, "Renewable Energy-Grouted Foundation Solutions", [Online], http://www.densit.com/Business_Areas/Renewable_EnergyGrouted_Foundation_Solutions/Ducorit\%C2\%AE.aspx

[26] I. Tavares, B. Wyatt, P. Ernst, G. John, and R. Jacob, 2015, "Corrosion Threats to Offshore Wind Foundations”, EWEA Offshore, Copenhagen, Denmark, PO.ID 095.

[27] D. Pearson, 2006, "Decommissioning Wind Turbines in the UK Offshore Zone", Enron Wind, pp. 22-26.

[28] C. Januário, S. Semino and M. Bell, 2007, "Offshore Wind farm Decommissioning: A Proposal for Guidelines to be Included in the European Maritime Policy”, Proc. of European wind energy conference, Milan, pp. 1-10.

[29] B. G. Foley, 2014, "Developments in Fixed Bottom Foundations and Sub-Structures in the US Market", Proc. AWEA Offshore, Atlanta.

$\begin{array}{lll}\text { Submitted: } & 20.10 .2015 . & \text { Jianhua Zhang, Issa Fowai } \\ & & \text { College of Aerospace \& Civil Engineering } \\ \text { Accepted: } & \text { 18.04.2016. } & \text { Ke Sun*, corresponding author, heusunke@ 126.com } \\ & & \text { College of Shipbuilding Engineering, Harbin Engineering } \\ & \text { University, Harbin, China }\end{array}$

